\title{
Tratamento de fratura dentária em atleta: relato de caso
}

\author{
Treatment of dental fracture in an athlete: case report \\ Tratamiento de fractura dental en atleta: reporte de caso \\ Gisely Naura VENÂNCIO' \\ Paulo Henrique Muller CALDERON ${ }^{2}$ \\ Francisco Pantoja BRAGA FILHO ${ }^{3}$ \\ Mateus Silva de SOUZA \\ Sarah Emília Chagas VENTILARI ${ }^{5}$ \\ Francisco Pantoja BRAGA ${ }^{2}$ \\ ${ }^{I}$ Doutoranda em Ciências Odontológicas - Área de Concentração Clínicas Odontológicas, Faculdade São Leopoldo Mandic \\ 13045-755 Campinas-SP, Brasil \\ ${ }^{2}$ Professor da Escola Superior de Ciências da Saúde, Universidade do Estado do Amazonas UEA \\ 69050-010 Manaus-AM, Brasil \\ ${ }^{3}$ UniNorte Manaus, 69020-031 Manaus-AM, Brasil \\ ${ }^{4}$ Mestre em Odontologia, Universidade Federal do Amazonas UFAM 69067-005 Manaus-AM, Brasil \\ ${ }^{5}$ Cirurgiã-Dentista, Universidade Nilton Lins, Manaus-AM 69058-030, Brasil
}

\section{Resumo}

Devido ao crescimento de praticantes de atividade esportiva houve um aumento do índice de traumatismo dentário. Desta maneira, o presente trabalho tem como objetivo descrever o caso clínico de um atleta com fratura dentária do elemento 11 . Paciente de 14 anos, sexo masculino, compareceu à Clínica de Odontologia da Universidade Nilton Lins, queixando-se de fratura de dente anterior durante a prática de esporte. Após anamnese e exame clínico, optou-se pela restauração direta em resina composta do elemento fraturado e confecção do protetor bucal, como plano de tratamento, a fim de evitar traumas posteriores. Pode-se concluir que a restauração em resina composta direta do dente anterior fraturado foi realizada de maneira satisfatória, restabelecendo função e estética, além da harmonia do sorriso e a autoestima do paciente e que o uso de protetores bucais é importante para a prevenção de futuros traumas dentários durante a prática desportiva.

Descritores: Traumatismos em Atletas; Resinas Compostas; Traumatismos Dentários; Protetores Bucais.

\section{Abstract}

Due to the growth of sports activity practitioners there was an increased dental trauma index. Thus, this study aims to describe the clinical case of an athlete with dental fracture of the element \#11. A 14-year-old male patient, attended at the Dental Clinic of University Nilton Lins, complaining of anterior tooth fracture during the practice of sport. After anamnesis and clinical examination, it was decided to restore the element with direct composite resin and making the mouthguard as treatment plan in order to avoid further trauma. It can be concluded that the restoration of direct composite resin fractured front tooth was carried out satisfactorily, restoring function and aesthetics, beyond the smile harmony and the patient's self-esteem and that the use of mouthguards is important for prevention of future dental trauma during sports.

Descriptors: Athletic Injuries; Composite Resins; Tooth Injuries; Mouth Protectors.

\section{Resumen}

Debido al crecimiento de practicantes de actividad deportiva hubo un aumento del índice de traumatismo dental. De esta manera, el presente trabajo tiene como objetivo describir el caso clínico de un atleta con fractura dental del elemento 11 . Paciente de 14 años, sexo masculino, compareció la Clínica de Odontología de la Universidad Nilton Lins, quejándose de fractura de diente anterior durante una práctica de deporte. Después de anamnesis y examen clínico, se optó por la restauración directa en resina compuesta del elemento fracturado y confección del protector bucal, como plan de tratamiento, a fin de evitar traumas posteriores. Se puede concluir que una restauración en resina compuesta directa diente anterior fracturada para la realización de la tarea satisfactoria, restableciendo la función y la estética, al igual que la armonía del amor y la autoestima del paciente y el uso de protectores para la prevención futuros traumas dentales durante una práctica deportiva.

Descriptores: Traumatismos en Atletas; Resinas Compuestas; Traumatismos de los Dientes; Protectores Bucales.

\section{INTRODUÇÃO}

O número de praticantes de atividade esportiva aumentou nos últimos anos, havendo um aumento também do traumatismo dentário decorrente desta prática ${ }^{1,2}$, estando as fraturas dentais e as avulsões entre as mais prevalentes lesões dentais apontadas por fisioterapeutas das principais equipes de futebol profissional brasileiro ${ }^{3}$.

O tratamento de um elemento dentário fraturado depende do tipo de fratura e das estruturas envolvidas, devendo-se levar em consideração o estado de saúde do paciente, a idade, a oclusão, bem como a extensão das fraturas, que podem ser: trincas de esmalte, fratura coronária não complicada (fratura de esmalte ou esmalte-dentina que não envolve a polpa), fratura coronária complicada (fratura de esmalte-dentina com exposição pulpar) e fratura coronoradicular - complicada ou não complicada (fratura de esmalte, dentina e cemento com ou sem exposição pulpar) ${ }^{3-5}$.

As alternativas terapêuticas são variadas, tais como: colagem de fragmento, restauração direta com resina composta, restauração indireta e/ou ainda tratamento endodôntico, conforme a quantidade de estrutura dental sadia e o comprometimento pulpar ${ }^{6}$.

Uma forma de impedir ou reduzir as inúmeras fraturas que acometem os praticantes de atividade esportiva é o uso do protetor bucal $^{7,8}$. Desta forma, a Associação Brasileira de Odontopediatria recomenda a utilização de dispositivos de proteção, incluindo placas intraorais, que têm a função de auxiliar na distribuição de forças de impacto, reduzindo o risco de lesão severa. Assim, o protetor bucal é de uso obrigatório em algumas modalidades ${ }^{8}$, apesar de não ser uma prática comum identificada entre os jogadores de futebol profissional $^{3}$.

O uso de protetor bucal durante atividades esportivas é altamente indicado para a prevenção de injúrias sendo a técnica de confecção relativamente simples, podendo ser realizada no próprio consultório odontológico 9 . Existem diferentes tipos de protetores bucais, cada um apresentando diferentes graus de proteção e consequentemente com indicações específicas ${ }^{10}$ e podem ser classificados em: tipo I (estoque), tipo II (termoplástico) e tipo III (feito sob medida $)^{11}$.

Desta maneira, o presente trabalho tem como objetivo descrever o caso clínico de um atleta com fratura coronária não complicada do elemento 11 , onde optou-se pela restauração dentária com resina composta direta com guia de silicone e confecção do protetor bucal, para restabelecer estética, função e evitar traumas posteriores.

\section{CASO CLÍNICO}

Paciente leucoderma, 14 anos de idade, sexo masculino, acompanhado da sua responsável, procurou atendimento odontológico, queixando-se do aspecto do seu sorriso devido à fratura de um dente anterior, ocorrida durante 
um jogo de futebol há mais de 1 ano (Figura 1).

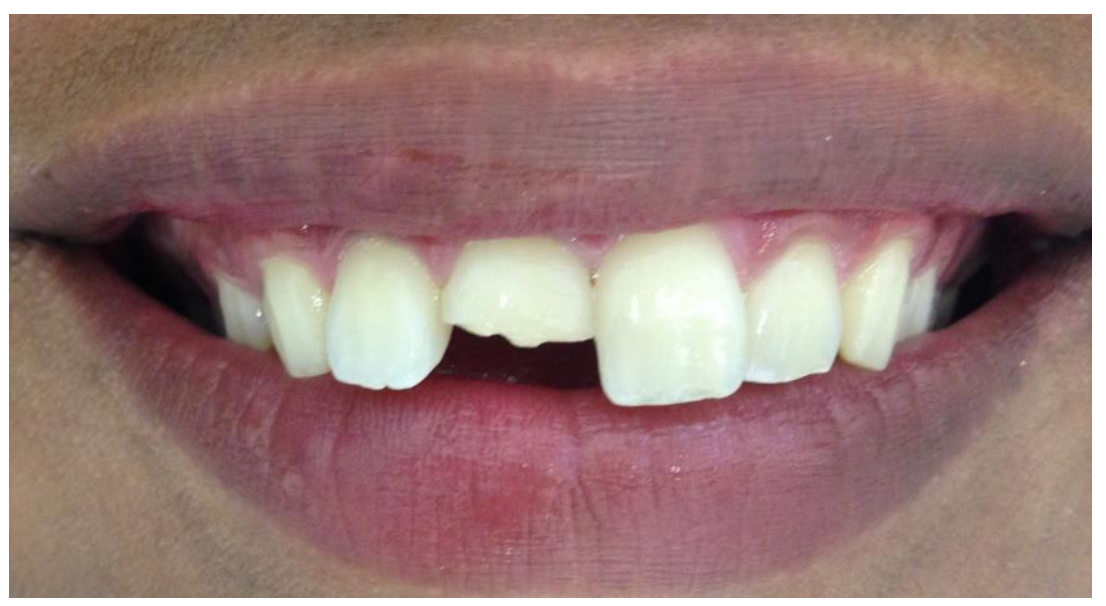

Figura 1: Aspecto inicial do sorriso do paciente.

$\mathrm{Na}$ anamnese verificou-se que o paciente possuía boa saúde geral. Ao exame clínico observou-se a fratura transversal, ao nível médio do elemento 11 , sem qualquer alteração de cor e o teste de vitalidade pulpar ao frio com Endo Ice (Maquira Dental, Maringá, Paraná, Brasil) deu positivo. Ao exame radiográfico constatou-se pequena reabsorção radicular devido ao trauma, ausência de comprometimento pulpar e de lesão periapical, bem como a ausência de fratura radicular (Figura 2).

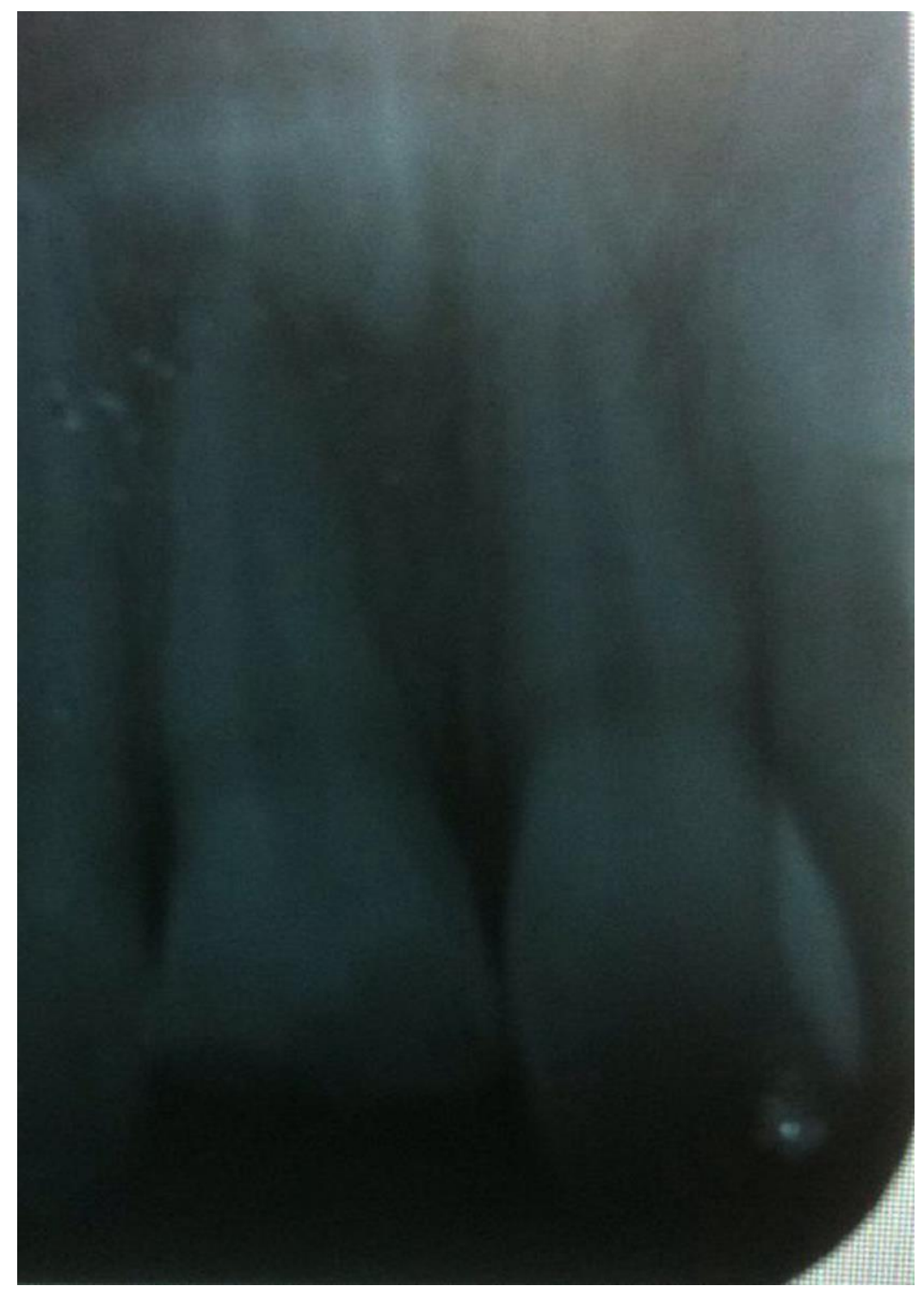

Figura 2: Radiografia periapical do elemento 11

Após assinatura do termo de consentimento livre e esclarecido (TCLE) pela responsável do paciente, o tratamento proposto constituiu em: restauração com resina composta direta do elemento 11 utilizando guia de silicone e confecção de protetor bucal para o uso do paciente durante a atividade desportiva.

O paciente foi encaminhado a um centro de imagem em Odontologia para a obtenção dos modelos e registro de mordida para posterior enceramento e diagnóstico em laboratório.

Após o enceramento do modelo, o paciente retornou à clínica para a restauração em resina composta direta do elemento 11. Primeiramente selecionou-se a cor da resina utilizando o auxílio da escala Vita (VITA Zahnfabrik, Sackingen, Alemanha), sob luz natural, atribuindo cor B1 para a dentina e A2 para o esmalte (Resina Filtek Z350 XT, 3M ESPE, SP, Brasil).

Em seguida foi confeccionada uma matriz personalizada de silicone (Heraus, Optosil Comfort Putty, RJ - Brasil) para orientação da parte palatina e altura incisal da restauração sobre o modelo de trabalho encerado.

Após profilaxia, realizou-se o isolamento relativo modificado do campo operatório e a prova da matriz de silicone, verificando sua adaptação na área a ser restaurada. Primeiramente foi realizado um sulco de orientação na região cervical da face vestibular com broca \#1012 e sulcos de orientação verticais com broca \#4138, unindo-se as canaletas em seguida, respeitando-se as inclinações cervical e média do dente, já que a porção incisal havia sido perdida devido ao trauma, obtendo-se assim um término supragengival e um desgaste da face vestibular compatível com a metade do diâmetro da broca. Após isso foi confeccionado um bisel na face vestibular correspondente à "incisal" do dente com broca \#2200. Fez-se então o condicionamento ácido da superfície por 30 segundos em esmalte e 15 segundos em dentina com ácido fosfórico a 37\% (DFL, São Paulo - SP - Brasil), seguido de lavagem abundante e secagem. Aplicou-se o adesivo (3M ESPE, St. Paul, MN, EUA) fotopolimerizando por 20 segundos na face vestibular e palatina.

Com uma espátula Suprafill (Duflex, SS White, São Paulo, Brasil) foi inserida uma fina camada de resina cor A2 junto à guia de silicone para reproduzir o esmalte da porção palatina e, após a verificação da adaptação entre a resina e a estrutura dentária (Figura 3), foi feita a polimerização durante 40 segundos.

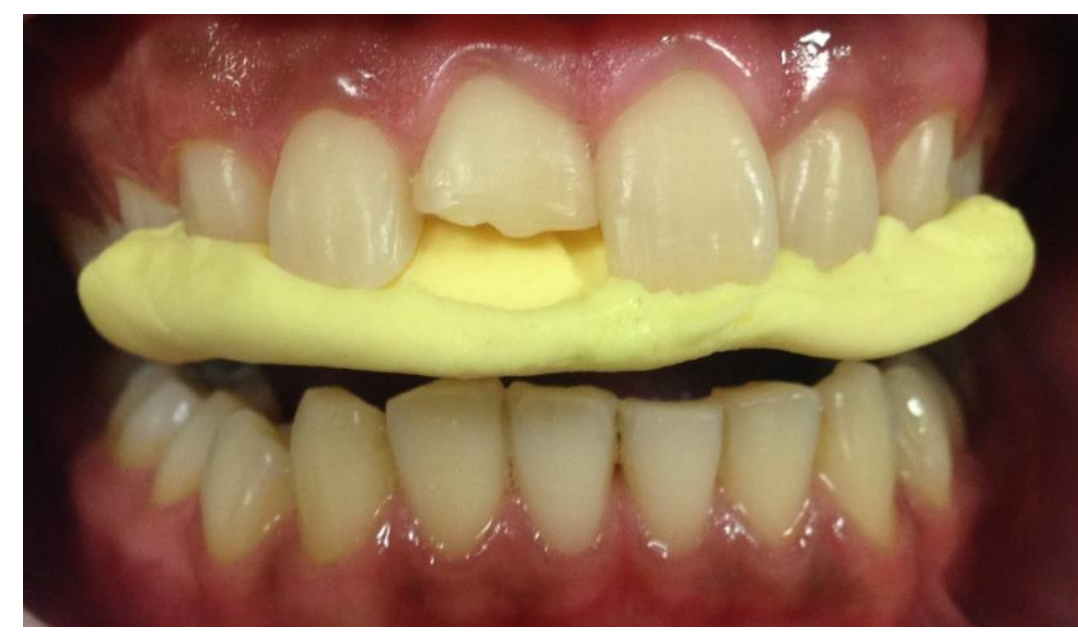

Figura 3: Guia de silicone em posição para a restauração da face palatina

Após a remoção da guia de silicone iniciou-se a reconstituição da porção de dentina, inserindo incrementos de resina B1 de corpo, seguida da porção vestibular de esmalte na cor A2, fotopolimerizando cada incremento por 40 segundos, reproduzindo as características naturais do elemento dentário.

O acabamento foi realizado com brocas diamantadas com granulação fina e extra-fina, brocas multilaminadas, além de discos sof-lex (TDV, Praxis, MN, USA), após verificação dos contatos oclusais em máxima intercuspidação habitual, protusiva, lateralidade esquerda e direita.

Após o término da restauração, o paciente foi moldado com silicone de condensação para a obtenção de um novo modelo de trabalho com o objetivo de se confeccionar o protetor bucal do paciente (Figura 4).

Após uma semana, realizou-se o polimento da restauração com brocas multilaminadas e pontas de silicone (Enhance, Dentsply, São Paulo, Brasil), apresentando a restauração um aspecto estético e natural (Figura 5).

O protetor bucal do tipo III foi confeccionado utilizando-se duas placas de polivinil acetato de $3 \mathrm{~mm}$ de espessura em plastificadora à vácuo, feito em duas etapas, 
conforme Figura 6

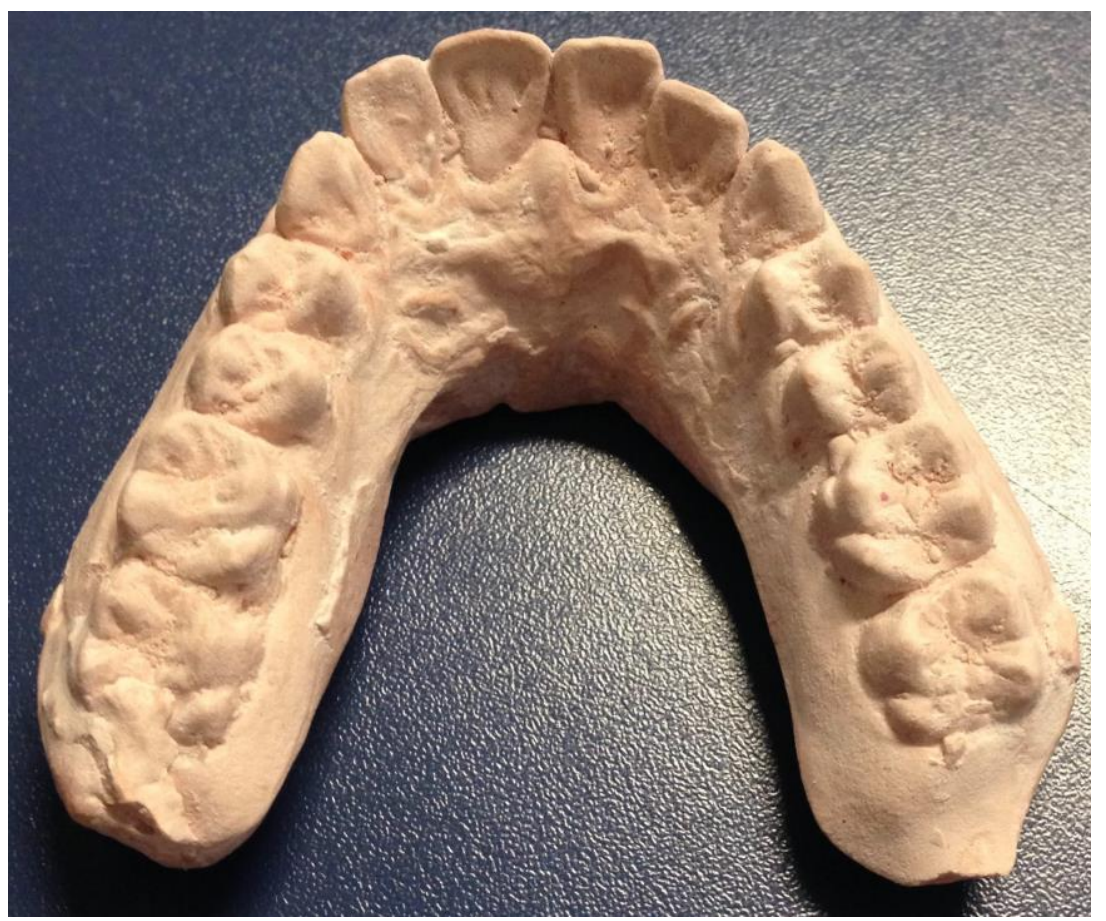

Figura 4: Modelo de trabalho após término da restauração.

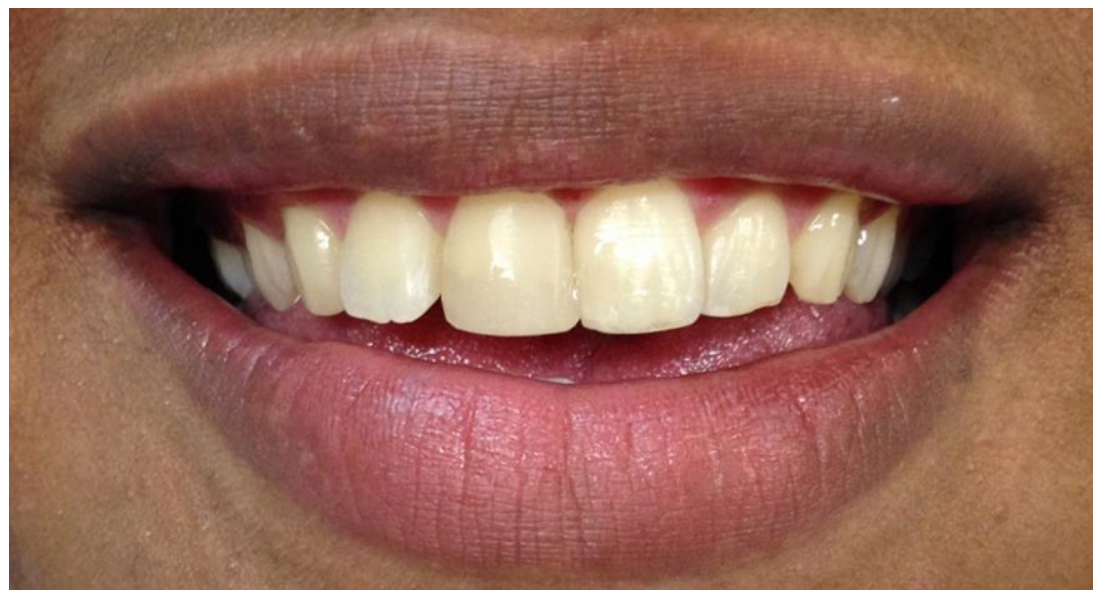

Figura 5: Aspecto final do sorriso.

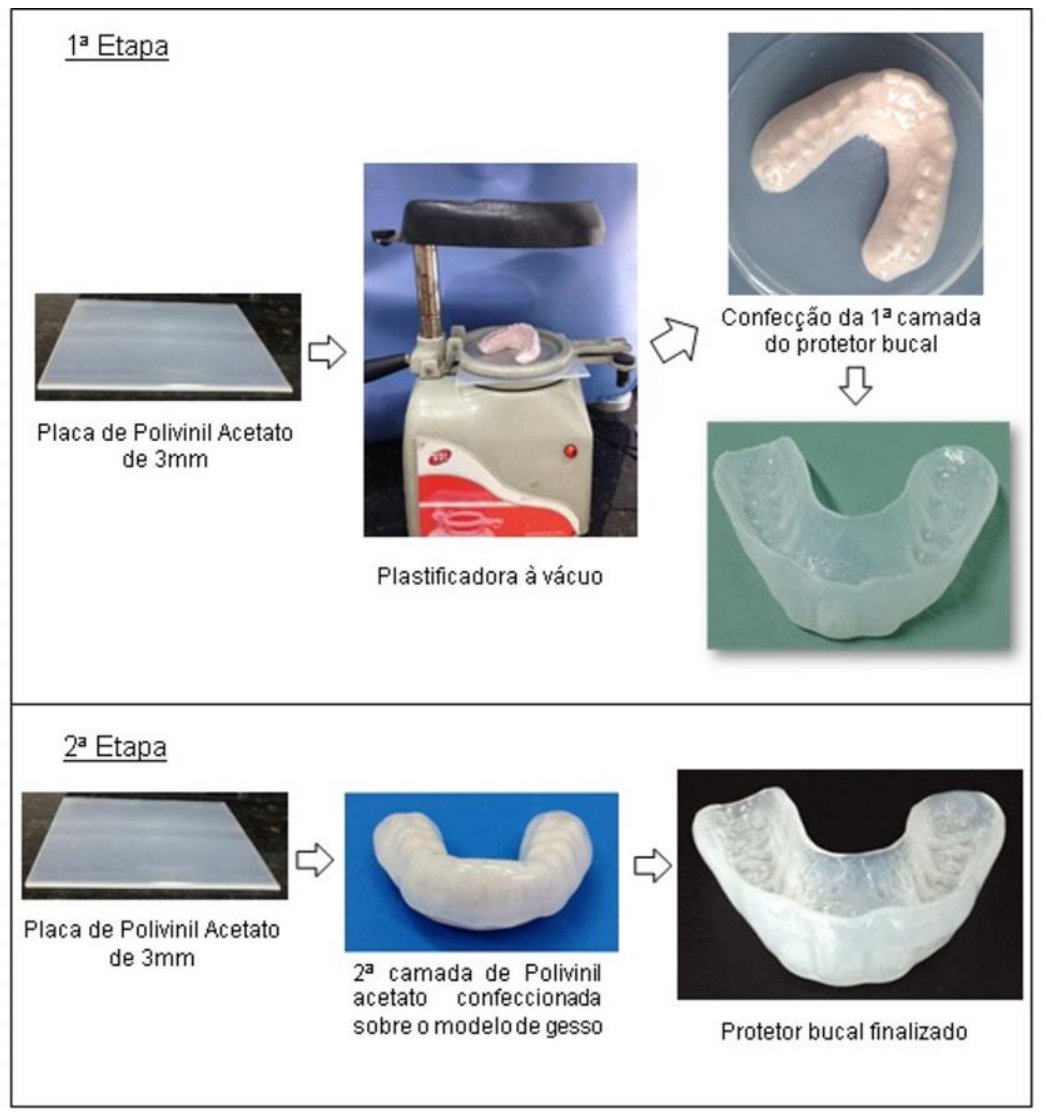

Figura 6: Etapas de confecção do protetor bucal do tipo III.

Depois disso a superfície oclusal do protetor bucal foi aquecida com uma lâmpada à álcool e o paciente mordeu para que os contatos oclusais ficassem devidamente distribuídos, finalizando assim a etapa de entrega do protetor bucal (Figura 7), com o objetivo de prevenir futuros traumatismos dentários, já que o paciente tem o hábito de jogar futebol e praticar outros esportes de contato. Foram dadas orientações ao paciente quanto à higienização e manutenção do dispositivo.

Após 6 meses (Figura 8) e após 1 ano (Figura 9), o paciente foi agendado para acompanhamento e proservação, onde foi realizado novo exame radiográfico, novo teste de vitalidade pulpar, além de análise da oclusão e foi realizado um novo polimento da restauração.

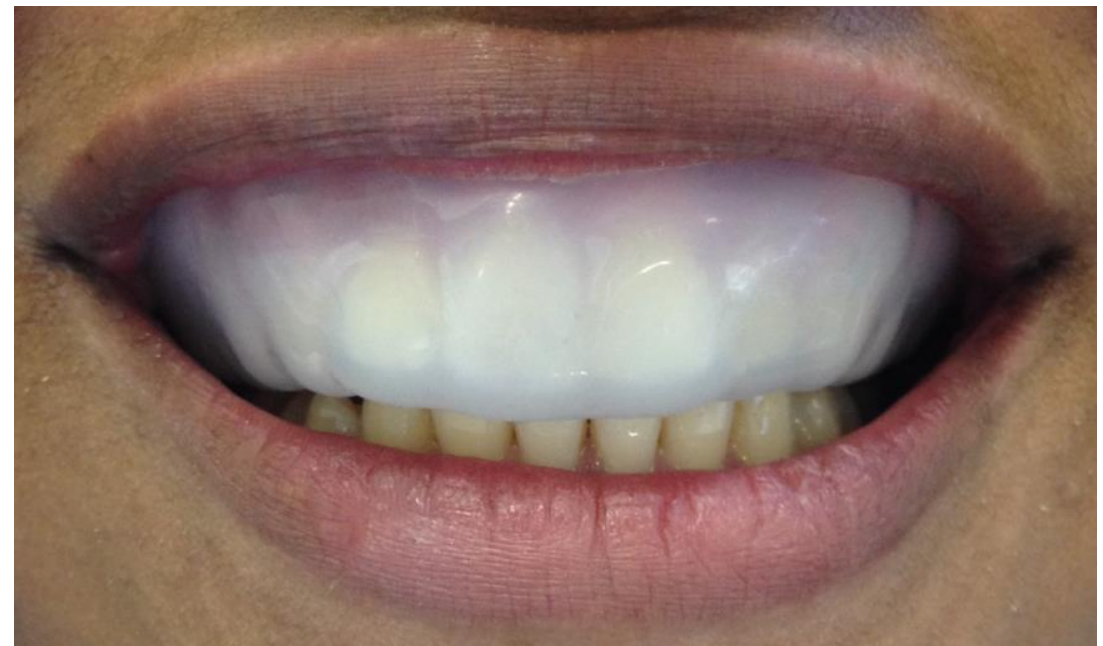

Figura 7: Protetor bucal.

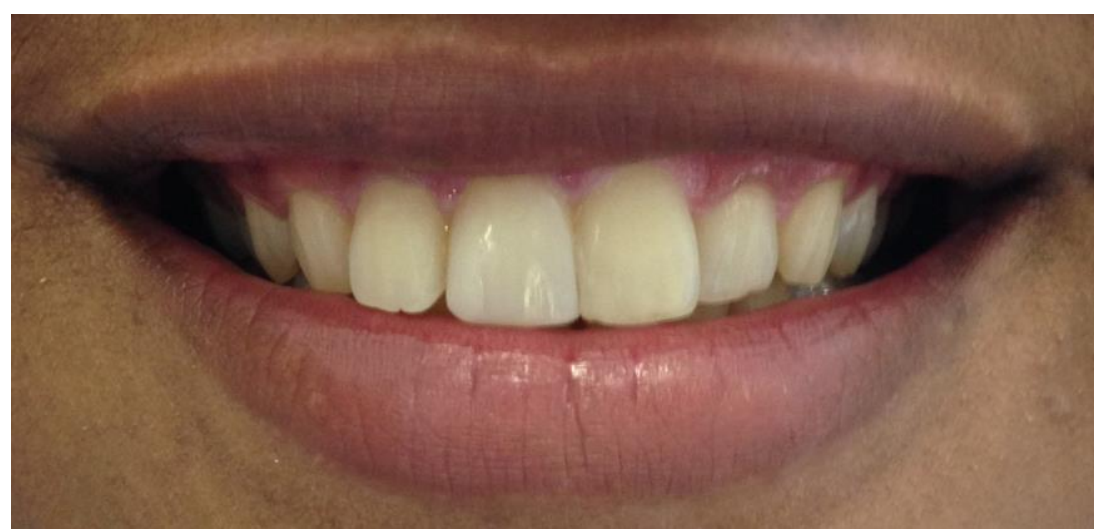

Figura 8: Sorriso do paciente após 6 meses da restauração.

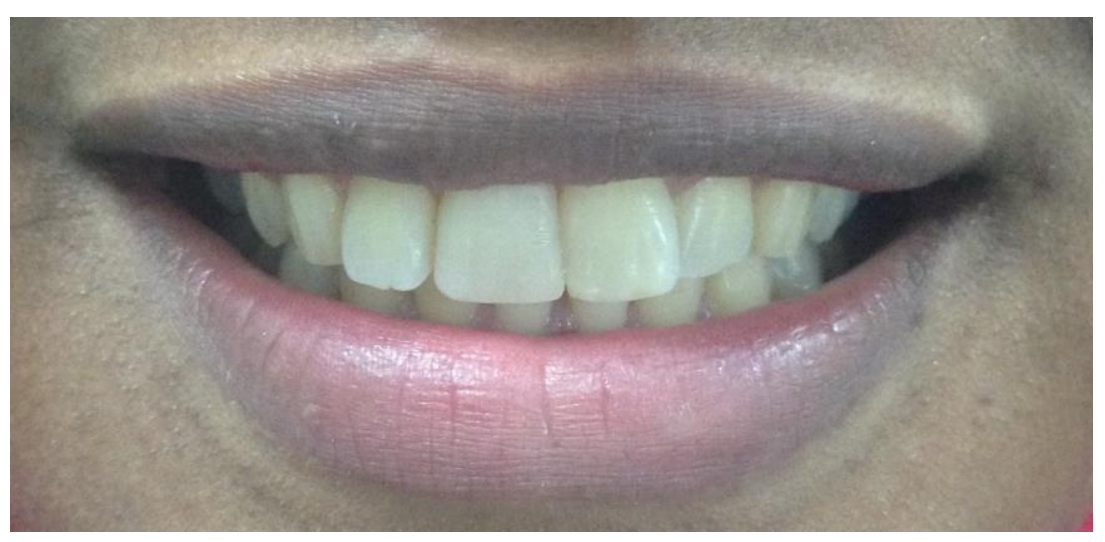

Figura 9: Sorriso do paciente após 1 ano da restauração.

\section{DISCUSSÃO}

Segundo Silva et al. ${ }^{12}$ e Wang et al. ${ }^{13}$, para a reabilitação de dentes fraturados resultante de traumatismo, é imprescindível elaborar um planejamento seguro para a aquisição de um prognóstico positivo, assim a avaliação radiográfica torna-se de suma importância para verificar o comprometimento pulpar ou periodontal e detectar a presença de possíveis fraturas radiculares. No presente caso, verificouse que a fratura era restrita ao esmalte e à dentina, não havendo envolvimento pulpar ou fratura radicular, tornando o prognóstico favorável.

O cirurgião-dentista possui grande quantidade de opções de tratamentos restauradores para dentes anteriores com fraturas coronárias, por isso é importante avaliar as expectativas do paciente e as possíveis soluções terapêuticas antes de iniciar qualquer planejamento. Sobre isso, Silva et al. ${ }^{8}$ afirmaram que escolha da técnica deve ser minuciosamente estudada de acordo com as possibilidades e necessidades de cada paciente, entretanto, sempre que possível, a colagem do fragmento autógeno deve ser preferida por aliar conservação de estrutura com excelentes resultados funcionais e estéticos.

Apesar da colagem de fragmento ser a primeira opção de tratamento nos casos de fraturas não complicadas ${ }^{8}$, tal procedimento não foi possível de ser realizado no caso apresentado, pois o paciente não possuía o fragmento dentário perdido e a fratura havia ocorrido há mais de 1 ano. Portanto, 
optou-se pela restauração direta do elemento fraturado com resina composta.

Tal procedimento é indicado por Silva et al. ${ }^{12}$, pois as principais técnicas para reconstrução de dentes fraturados utilizam materiais restauradores adesivos diretos por possuírem propriedades físicas e mecânicas semelhantes à estrutura dentária, além de ser uma técnica minimamente invasiva, rápida e de baixo custo. Além disso, no presente caso, a responsável pelo paciente solicitou que fosse realizado o tratamento mais rápido e barato possível, pois a mesma afirmou não ter condição financeira para realizar uma restauração indireta, onde haveria um gasto maior.

Nesse contexto, Oliveira e Ritter ${ }^{14}$ afirmaram que a escolha de resinas compostas para a restauração de um elemento dentário permanente com fratura coronária é uma opção de tratamento conservadora e econômica, além de recuperar a função e proporcionar ótimos resultados estéticos. Portanto, no presente caso, esse foi o tratamento de escolha, onde foi utilizada a resina composta do tipo nanoparticulada que, de acordo com Can et al. ${ }^{15}$, quando comparada à resina híbrida e microparticulada, possui maior eficácia nas propriedades mecânicas, pois é contituída por partículas de reforço em tamanho reduzido, oferecendo um elevado padrão de perfeição estética, além de permitir um excelente polimento superficial.

As resinas compostas atuais, em especial as de nanopartículas, conseguem reunir características mecânicas funcionais para regiões submetidas a altas tensões, com propriedades ópticas adequadas para o alcance de excelência estética em restauração de dentes anteriores ${ }^{16}$.

Dessa forma, aliada aos materiais, a técnica restauradora deve mimetizar as característica originais dos dentes anteriores, tornando as restaurações imperceptíveis ${ }^{8}$. Em dentes com fraturas amplas é interessante o recobrimento da face vestibular com resina composta com o objetivo de harmonizar o resultado estético. A possibilidade de restaurar de forma direta com resina composta sempre deve ser considerada, pois é uma alternativa que permite conservar mais estrutura dental com menor custo em comparação a técnicas indiretas ${ }^{17}$. Tal fato foi levado em consideração devido à própria escolha da responsável pelo paciente dentre as alternativas de tratamento apresentadas, onde ela priorizou a opção mais rápida e de menor custo.

Para a confecção de restaurações de resina composta a literatura afirma que o isolamento absoluto é a escolha mais eficaz para o controle da contaminação do ambiente bucal ${ }^{18}$. Porém, há vários estudos que equiparam o isolamento relativo, quando bem realizado, ao isolamento absoluto como forma de manutenção de um campo operatório e até mesmo no desempenho clínico de restaurações de resina composta $^{19,20}$. Assim, no presente caso, o isolamento relativo modificado, com roletes de algodão e expansor de boca e gazes, foi escolhido por ser uma região de fácil controle de umidade do meio bucal.

Conceição ${ }^{17}$ e Silva e Lund $^{21}$ concordam que, para a realização de facetas diretas em resina composta em dentes anteriores, está indicado realizar o isolamento relativo, pois possibilita uma visão mais ampla do campo operatório e a contínua análise da relação do dente com os tecidos gengivais do paciente. No caso apresentado, optou-se por seguir o protocolo de faceta direta de resina composta proposto por Conceição ${ }^{17}$, porém modificado, onde não houve desgaste da face palatina, utilizando-se a guia de silicone para restauração da face palatina de maneira mais prática pois, segundo Gonçalves et al. ${ }^{9}$ essa técnica facilita a obtenção de convexidades e contornos dentais e que seriam mais demorados e trabalhosos em uma técnica restauradora direta.

Contudo, Busato et al. ${ }^{22}$ afirmam que as resinas possuem desvantagens como instabilidade de cor, contração de polimerização e desgaste, o que pode ocasionar alterações em restaurações a curto prazo. Sobre tal fato, Silva e Lund ${ }^{21}$ acrescentam ainda que há limitações para a indicação de restaurações diretas de resina composta em dentes fraturados, tais como: perda de estrutura dentária superior a 50\%, pacientes com bruxismo, não colaboradores, que consumam muitos alimentos com corantes e que tenham má higiene oral. No entanto, nenhuma limitação foi encontrada no paciente do caso apresentado, tendo sido possível realizar o tratamento proposto.

No que se refere ao traumatismo dentário, Gonçalves et al. ${ }^{9}$ acreditavam que há uma particularidade que difere o traumatismo dentário no esporte daquele ocorrido em outras áreas, que é justamente a possibilidade de prevenção, reduzindo ou mesmo impedindo o número e a severidade das lesões nestas estruturas. Tal afirmativa deve-se à possibilidade de uso de protetor bucal durante atividades esportivas e, desta forma, Lima ${ }^{11}$ enfatizou que o dispositivo é altamente indicado para a prevenção de injúrias, sendo a técnica de confecção relativamente simples, podendo ser realizada no próprio consultório odontológico.

Segundo Gonçalves et al. ${ }^{9}$ os protetores bucais feitos sob encomenda são do tipo III e são o tipo ideal de proteção, pois são confeccionados pelo dentista após a obtenção de um modelo da maxila do paciente com placas de vinil, borracha, poliuretano com borracha, borracha de silicone, polivinil acetato ou com resina termoplastificada na máquina de conformação a vácuo. É o dispositivo mais retentivo, confortável e o que oferece melhor adaptação e proteção superior na prevenção de traumatismos. As alterações de fala e respiração são mínimas.

Para Lages et al. ${ }^{10}$ os protetores personalizados são os que possuem a adaptação mais precisa e por isso absorvem mais impactos e reduzem o número de lesões, quando comparados aos outros tipos. Dessa forma, o uso de protetores bucais personalizados deve ser indicado para prática de esportes em detrimento dos pré-fabricados. Devido a todas essas vantagens, optou-se pela confecção do protetor bucal personalizado com polivinil acetato transparente no caso apresentado e verificou-se uma ótima adaptação do paciente ao uso do protetor bucal, não havendo qualquer reclamação quanto a dor ou incômodo.

No presente caso, por ser uma fratura coronária não complicada em dente com vitalidade pulpar e, apresentando o paciente uma oclusão estável, foi possível realizar um procedimento restaurador conservador. $\mathrm{O}$ prognóstico se mostrou favorável devido à associação do tratamento restaurador ao uso do protetor bucal durante as atividades esportivas do paciente, prevenindo assim futuros traumatismos dentários.

\section{CONCLUSÃO}

A restauração em resina composta direta do dente anterior fraturado por trauma foi realizada de maneira satisfatória, com equilíbrio oclusal, devolvendo-se função, estética e dando longevidade ao dente, além da harmonia do sorriso e a autoestima do paciente, estando este consciente quanto à importância do uso do protetor bucal para a preservação da restauração e prevenção de traumas futuros durante a prática de esportes.

\section{REFERÊNCIAS}

1. Arslan, H, Barutcigil, Aladağ, H, kürklü, D. Management of fractured permanent incisors: 1 year follow-up. J. Contemp. Dent. Pract. 2011; 12(6):501-5.

2. Traebert J, Marcon KB, Lacerda JT. Prevalência de traumatismo dentário e fatores associados em escolares do município de Palhoça (SC). Ciênc. Saúde Colet. 2010; 15(supl 1):1849-55.

3. Correa MB, Schuch HS, Colares K, Torriani DD, Hallal PC, Demarco FF. Survey of the occurrence of dental 
trauma and preventive strategies among professional soccer players. J Appl Oral Sci. 2010; 18(6):572-6.

4. Daneshvar DH, Baugh CM, Novinsky CJ, McKean AC, Stern RA, Cantu RC. Helmets and mouth guards: the role of personal equipment in preventing sport-related concussions. Clin. Sports Med. 2011; 30(1):145-63.

5. Losso EM, Tavares MCR, Bertoli FMP, Baratto-Filho F. Traumatismo dentoalveolar na dentição decídua. RSBO. 2011; 8(1):e1-20.

6. Sharma D, Garg S, Sheoran N, Swami S, Singh G. Multidisciplinary Approach to the rehabilitation of a tooth with to trauma episody: systematic review and report of a case. Dent Traumatol. 2011; 27(4):321-6.

7. Freitas DA, Freitas VA, Antunes SLNO, Crispim RR. Avaliação do conhecimento de acadêmicos de educação física sobre avulsão/reimplante dentário e a importância do uso de protetor bucal durante atividades físicas. Rev bras cir cabeça pescoço. 2008; 37(4):215-8.

8. Silva GR, Waechter DM, Martins LRM, Barreto BCF, Soares CJ. Técnicas restauradoras para fraturas coronárias de dentes anteriores traumatizados. UNOPAR Cient Ciênc Biol Saúde 2012;14(4):251-6

9. Gonçalves AR, Albuquerque HCL, Ferreira MCC, Souza CHC. Protetores bucais: tipos e técnica de confecção. Prosthes Lab Sci. 2012; 2(5):61-8.

10. Lages FS, Rivera CP, Araújo DCE, Oliveira DWD. Protetor bucal para esportistas: relato de caso clínico. Rev FOL/Unimep. 2014; 24(2):32-6.

11. Lima DL. Odontologia esportiva: o cirurgião-dentista no cuidado do esportista. São Paulo: Santos, 2013.

12. Silva FP, Reis GR, Vilela ALR, Menezes MS Reabilitação estética de dente fraturado - relato de caso. Full Dent Sci. 2015; 6(22):249-55.

13. Wang C, Qin M, Guan Y. Analysis of pulp prognosis in 603 permanent teeth with uncomplicated crown fracture with or without luxation. Dent Traumat. 2014; 30(5): 333-7.

14. Oliveira GM, Ritter AV. Composite resin restorations of permanent incisors with crown fractures. Pediatr Dent. 2009; 31(2): 102-9.

15. Can Say E, Yurdagüven H, Yaman BC, Özer F. Surface roughness and morphology of resin composites polished with two-step polishing systems. Dent Mater. J. 2014; 33(3):332-42.

16. Calixto LR, Clareijo V, Kasbbach W, Andrade MF. Harmonização do sorriso com resina composta direta. dental press estét. 2009; 6(1):18-28.

17. Conceição EN. Dentística - Saúde e Estética. 2. ed. Porto Alegre: Artmed; 2007

18. Martos J, Nascimento CN, Collares KF, Silveira LFM. Trauma in permanent central incisor with crown fracture treated by direct restoration. J Pediatr Dent. 2013; 1(1): 24-6.

19. Pedrosa FAS, Silveira RR, Yamauti M, Castro CDL, Freitas ABDA. Isolamento do campo operatório: Panorama de utilização em consultórios e clínicas privadas de Belo Horizonte, MG, Brasil. Pesq Bras Odontoped Clin Integr. 2011; 11(3):443-9.

20. Soldani F, Foley J. An assessment of rubber dam usage amongst specialists in paediatric dentistry practicing within the UK. Int J Paediatr Dent. 2007; 17(1):50-6.

21. Silva AF, Lund RG. Dentística Restauradora: Do Planejamento à execução. Rio de Janeiro: Santos; 2016.

22. Busato ALS, Macedo RP, Reston EG, Barbosa AN, Sanseverino MD, Costa MCS et al. Redução ou fechamento de espaços interdentários. Stomatos. 2006; 12(22):19-23.

\section{CONFLITO DE INTERESSES}

Os autores declaram não haver conflitos de interesse.

\section{AUTOR PARA CORRESPONDÊNCIA}

Gisely Naura Venâncio

ginaura@gmail.com

Submetido em 09/03/2018

Aceito em 09/04/2018 